\title{
The Primary Care Extension Program: A Catalyst for Change
}

\author{
Robert L. Pbillips Jr, MD, MSPH \\ Artbur Kaufman, $M D^{2}$ \\ James W. Mold, MPH, MD ${ }^{3}$ \\ Kevin Grumbach, $M D^{4}$ \\ Molly Vetter-Smith, Med, RD, PbD \\ Anne Berry ${ }^{6}$ \\ Bridget Teevan Burke, MS, MPH \\ 'The American Board of Family Medicine \\ Washington, DC \\ ${ }^{2}$ Office for Community Health, University \\ of New Mexico, Albuquerque, New Mexico \\ ${ }^{3}$ Department of Family \& Preventive Medi- \\ cine, University of Oklahoma, Oklahoma \\ City, Oklahoma
}

${ }^{4}$ Department of Family and Community Medicine, University of California San

Francisco, San Francisco, California

${ }^{5}$ Office of Continuing Education \& Extension, University of Missouri, Kansas City, Missouri

${ }^{6}$ George Washington University, Trachtenberg School of Public Policy and Public Administration, Washington, DC

${ }^{7}$ Johns Hopkins Bloomberg School of Public Health, Baltimore, Maryland

Conflicts of interest: Drs Kaufman and Mold are botb recipients of IMPaCT grants, and have received prior federal research and state funds to support their extension programs. Drs Grumbach and Pbillips were members of the Institute of Medicine study cited in this paper.

\section{CORRESPONDING AUTHOR}

Robert L. Phillips Jr, MD, MSPH

The American Board of Family Medicine 1133 Connecticut Ave NW, Suite 1100

Washington, DC 20036

bphillips@theabfm.org

\begin{abstract}
The Affordable Care Act authorized, but did not fund, the Primary Care Extension Program (PCEP). Much like the Cooperative Extension Program of the US Department of Agriculture sped the modernization of farming a century ago, the PCEP could speed the transformation of primary care. It could also help achieve other goals such as integrating primary care with public health and translating research into practice. The urgency of these goals and their importance to achieving the Triple Aim for health care should increase interest in rapidly building the PCEP, much as the need to feed the country did a century ago.
\end{abstract}

Ann Fam Med 2013;11:173-178. doi:10.1370/afm.1495.

\section{INTRODUCTION}

$\mathrm{P}$ assage of the Affordable Care Act of 2010 (ACA) laid a foundation for unprecedented support of primary care, placing it at the core of a learning health care system that seeks to achieve the Center for Medicare and Medicaid Services' Triple Aim: improving the experience of care, improving the health of populations, and reducing per capita costs of health care. ${ }^{1}$ This article seeks to help clinical and policy leaders understand how critical the Primary Care Extension Program (PCEP) is to enhancing primary care effectiveness, to the integration of primary care and public health, and to translating research into practice, all with the goal of achieving the Triple Aim for health care.,

Before the ACA, primary care leaders were already engaged in designing and testing new models of care, particularly the patient-centered medical home $(\mathrm{PCMH})$. Evidence suggesting that these reformed models of primary care improve health outcomes while reducing costs has stimulated a surge of interest for widespread transformation of primary care. ${ }^{4,5}$ Many of these high-performing models have increased capacity for monitoring and managing population health, and some have bridged the substantial gap between primary care and public health. ${ }^{6,7}$ Despite early evidence and growing enthusiasm, primary care transformation has not yet arrived at a tipping point, and the United States lacks a mechanism for facilitating the change.

\section{PRIMARY CARE EXTENSION PROGRAM}

Anticipating these challenges to primary care transformation, the ACA authorized the Agency for Healthcare Research and Quality (AHRQ) to create a national the PCEP. This section of the law states that the principal charge of the PCEP is to "assist primary care providers to implement a patient-centered medical home to improve the accessibility, quality, and efficiency of primary care services" through local deployment of community-based Health Extension Agents. In addition to their practice facilitation roles, these agents may "collaborate with local health departments, community health centers, tribes and tribal entities, and other community agencies to identify community health priorities and local health 
workforce needs, and participate in community-based efforts to address the social and primary determinants of health, strengthen the local primary care workforce, and eliminate health disparities." This concept is not new, and these local change-agents have previously been referred to as "practice coaches," "practice facilitators," or "practice enhancement assistants."

Though no funding was allocated for a primary care extension program, AHRQ used existing appropriations to launch a pilot initiative in 2011 called Infrastructure for Maintaining Primary Care Transformation (IMPaCT). IMPaCT awards are supporting PCEPs in 4 states, each serving as a lead for disseminating PCEP activities to 3 additional neighboring states.

With IMPaCT, the potential value of a national primary care extension program has come into sharper focus. It has also become more apparent how a primary care extension program could support efforts to improve primary care effectiveness, such as those of the Center for Medicare \& Medicaid Innovation. Additionally, the Institute of Medicine Committee on the Integration of Primary Care and Public Health recently released a report stressing the need to develop stronger partnerships between primary care and public health to improve population health. ${ }^{7}$ This Institute of Medicine study specifically mentions the PCEP as an important model for developing these partnerships.

\section{Roots in the Department of Agriculture's Cooperative Extension}

The PCEP builds upon the US Department of Agriculture's (USDA) highly effective Cooperative Extension. For nearly 100 years, county extension agents worked with farmers to identify their needs, build trust, and translate research-based knowledge emerging from landgrant universities and experimental farms-all to speed adoption of best farming practices. ${ }^{9}$ The Cooperative Extension is publically funded through cooperative arrangements between the USDA, states, and the local counties. Cooperative Extension agents are imbedded in every county, developing personal relationships and understanding of the local context. In a 1991 economic impact study of the Cooperative Extension, researchers at Yale and the World Bank described the translation of this successful model around the world:

Agricultural extension services are one of the most common forms of public-sector support of knowledge diffusion. Effective agricultural extension can bridge the gap between discoveries in the laboratory and changes in the individual farmer's fields. In addition to information about cropping techniques, optimal input use, high-yield varieties, and prices, extension agents can inform farmers about improved record keeping and aid in the development of their managerial skills, thus facilitating a shift to more efficient methods of production. By accelerating the diffusion process of improved technology, extension can bring about a faster growth of yields and rural incomes than would occur in the absence of extension. Agricultural extension services not only convey information from research centers to farmers but also can ease a reverse flow of information. In many countries extension services function as farmer organizations, expressing farmer concerns to the public agencies designed to serve farmers. ${ }^{10}$

They document that the World Bank supported uptake of agricultural extension in 79 countries between 1965 and 1986 and found that by 1980 low-income countries were spending as much on extension as on agricultural research. More importantly, 36 of the 48 studies they reviewed found significant, positive effect for increased agricultural production and profits, in both developed and underdeveloped countries. Overall rates of return ranged from $13 \%$ to $500 \%$. In 2009, the Hawaii Department of Agriculture reported a 32\% return on investment for their Cooperative Extension program. ${ }^{11}$ Dr Donald Berwick wrote nearly a decade ago about the need for a similar resource in health care. ${ }^{12}$

\section{Evidence}

There is growing evidence that local change agents can also successfully facilitate quality improvement in primary care practices. In a recent meta-analysis of 23 separate studies, Baskerville concluded that "primary care practices are $2.76(95 \% \mathrm{CI}, 2.18-3.43)$ times more likely to adopt evidence-based guidelines through practice facilitation." ${ }^{\prime 13}$ Several of the studies included in the meta-analysis were conducted in the Oklahoma Physicians Resource/Research Network (OKPRN). During the past 12 years, researchers at the University of Oklahoma Department of Family and Preventive Medicine have helped practices improve delivery of preventive services, manage patients with chronic disease, and use health information technologies. ${ }^{14-18}$

Another PCEP prototype that has placed particular emphasis on a population health framework is the Health Extension Rural Office (HERO) program coordinated by the University of New Mexico. ${ }^{19}$ The HERO program partners with communities in every county of the state, identifying community health needs and mobilizing academic health center resources to meet those needs. HERO has trained and deployed community health workers to areas of need in support of primary care practices. ${ }^{20}$

\section{Cost Effectiveness}

A 2005 study of practice facilitation in Canada found net savings of $\$ 3,687$ per physician and $\$ 63,911$ per outreach facilitator. ${ }^{21}$ The Canadian researchers estimated a $40 \%$ return on intervention investment and delivery 
of appropriate preventive care. Grumbach et al recently summarized 2 systematic reviews of "practice coaching" which included 27 randomized trials. ${ }^{8}$ The majority of the trials found that practice coaching improved chronic and preventive care and increased willingness to implement changes, and that the effect was improved with increased intensity and duration of coaching. ${ }^{12,22}$

\section{Value of the PCEP to Health Reform Priorities and Health Outcomes}

Strengthened and reengineered primary care is central to many of the initiatives underway to reform health care and improve health. Beyond authorization of the PCEP, the ACA created new programs specifically targeting primary care, such as the Comprehensive Primary Care Initiative and the Multi-payer Advanced Primary Care Practice Demonstration. Other ACA programs would transform health centers into patientcentered medical homes, establish community health teams, and broaden chronic and preventive care for Medicaid beneficiaries. ${ }^{23}$ More than 40 states have launched PCMH demonstrations, there are 68 multistakeholder $\mathrm{PCMH}$ pilots underway in 25 states, and in 2010, more than 5 million patients were enrolled in PCMH demonstration programs supported by private insurance plans and state Medicaid programs. ${ }^{24,25}$ For example, the parent companies of the Blue Cross and Blue Shield Association and 27 of its subsidiaries recently adopted a nationwide $\mathrm{PCMH}$ demonstration initiative. ${ }^{26}$ Although many demonstrations and other programs are in play across the nation, few have clearly articulated strategies for building and sustaining the infrastructure needed for ongoing practice facilitation. Attending to such an infrastructure was a strong message from the Institute of Medicine. ${ }^{9}$

Nearly one-third of practices are still solo or 2 -physician practices, many serving small communities. ${ }^{27}$ These practices benefit from strong patient and community relationships, and can, with appropriate assistance, adopt innovations and make changes in processes of care more rapidly than can large health care systems; however, small practices operate under greater time constraints, employ fewer staff, have narrower margins, and have little time for reflection and relationship building. ${ }^{28}$ Vermont is a leader in systematic movement of practices to advanced practice models through its Blueprint for Health initiative, which includes teams of practice facilitators for small and independent practices. ${ }^{29}$ Vermont's effort is supported by a number of private and public payers.

There is a precedent for federal support of health services facilitation. The Regional Extension Centers program was implemented under the Health Information Technology for Economic and Clinical Health
(HITECH) Act, enacted as part of the American Recovery and Reinvestment Act to help practitioners and hospitals adopt electronic health records. These regional extension centers received nearly $\$ 700$ million since 2010 to support health information technology adoption, but federal funding for regional extension centers is slated to end in $2013 .{ }^{30}$ Existing PCEPs, such as OKPRN, have also worked with primary care practices to facilitate uptake of health information technologies. There is an opportunity to consider how the regional extension centers and PCEP might be melded for a sustainable program of practice improvement facilitation that includes meaningful use of health information technology as one of its charges.

Growing interest in the integration of primary care and public health is yet another opportunity for considering how the PCEP could advance current health reform priorities. The ACA funded the Community Transformation Grants program administered by the Centers for Disease Control and Prevention. These grants require interventions in public health and primary care to improve community health. The recent Institute of Medicine report Primary Care and Public Health: Exploring Integration to Improve Population Health also speaks to this interest. The report states that successful integration requires sustainable local infrastructure with the capacity to "manage change" and recommends the PCEP as a means to "create linkages between primary care providers and their local health departments. ${ }^{17}$ The New Mexico HERO program suggests how an extension program could help bring together these sectors by building bridges to community resources formerly isolated from primary care practice, such as access to food banks for indigent primary care clinic families, mobilizing assistance from the Cooperative Extension Service to offer nutrition classes to patients, creating primary care-linked community health worker training programs in community colleges, and partnering with public health departments in arranging addiction treatment for primary care patients. The University of Oklahoma county-based Turning Point partnerships are also being encouraged to partner with local primary care providers to form "county health improvement organizations."

A final area of alignment between the PCEP and federal priorities for health care improvement is translational research. The National Institutes of Health (NIH) launched the Roadmap for Biomedical Research, "to speed scientific discovery and its efficient translation to patient care." ${ }^{11}$ The Clinical Translation Science Awards are an important embodiment of that goal of shortening the distance from discovery to patient care and meaningfully engaging communities. The institutions with Clinical Translation Science Awards have 
to invent the infrastructure and staffs to meet these 2 goals, and most are struggling. The PCEP could help them by bridging the town-gown gap through the relationships it would forge with practices and communities. The PCEP could be the catalyst that the NIH and Clinical Translation Science Awards need to improve the efficiency and effectiveness of research translation.

There are many aspects of the ACA and other federal and state health reform efforts that would benefit from having an agent on the ground in every community who can be a catalyst for change and connection. The biomedical research infrastructure of this country would similarly benefit from the catalytic capacity of the PCEP.

\section{Financial Sustainability}

The AHRQ recently released Developing and Running a Primary Care Practice Facilitation Program: A How-to Guide in which they offer several financial models. ${ }^{32}$ Two types of funding are likely to be important: sustaining funding and project-specific funding. In addition to federal funding, the guide suggests that state and local governments, including Medicaid programs, hospitals, private health insurance companies, and local businesses, could expect to gain financially from their investment and be willing partners.

Project-specific funding could come from several sources, including federal (eg, Center for Medicare and Medicaid Innovation, Office of the National Coordinator for Health Information Technology, CDC, Health Resources Services Administration, NIH, Department of Defense, and AHRQ), state (eg, tobacco settlement funds), and local (eg, local governments, businesses, and donors), as well as private foundations, other nonprofits (eg The Patient-Centered Outcomes Research Institute), and local industries.

Several existing examples show how PCEP programs have successfully woven together funding from a variety of governmental and private sources. In New Mexico, sustaining funding for HERO comes from Medicaid Managed Care plans, such as Molina Healthcare, Inc, community hospitals, and the academic health center. Molina Healthcare, Inc, pays for HERO to train, hire, and deploy community health workers across counties in which they have substantial enrollment. ${ }^{33}$ The success of this program in improving care quality while reducing utilization motivated Molina to roll this program out in 10 other states. Four community hospitals in New Mexico now hire HERO staff to link primary care practices to university resources and help conduct community health surveys. The University of New Mexico's Clinical Translational Science Center now allocates $10 \%$ of the salaries of 10 HEROs across the state to identify community and practice health priorities and partner with university investigators in addressing those priorities.

In Colorado, HealthTeamWorks offers practices free coaching for making the transition to a PCMH thanks to funding from 3 foundations and a state agency. ${ }^{34}$ HealthTeamWorks employs 10 coaches focused on practice transformation, initially at no cost to practices. Similarly, the University of California San Francisco Center for Excellence in Primary Care is providing practice coaching for safety net clinics supported by a combination of foundation grants, the local Department of Public Health, and Medicaid funds through a Medicaid waiver. Business models will necessarily differ across communities and practice settings. ${ }^{8}$

\section{CONCLUSIONS}

There is tremendous urgency to accelerate changes in primary care, integrate primary care with public health, and translate research into practice to improve health outcomes, health care, and costs. The PCEP is important for the success of many programs implemented by the ACA, from integrating primary care and public health to translating research into practice. Many practices are aware of new models of care, but few have the time or resources to understand or implement them. Many communities are the recipients of ACA grants and programs but have little support to coordinate with primary care practices. These practices and communities could benefit from the help of Health Extension Agents.

The Cooperative Extension and early models of the PCEP indicate that investment to broaden implementation of PCEP programs would have good returns. Buyin from private payers in several states suggests that federal leadership can leverage matching support from other financial stakeholders. The USDA's annual budget for all of its extension activities was $\$ 494$ million in 2010. ${ }^{35}$ A similar federal investment in the PCEP, partnerships with existing federal programs like Area Health Education Centers and Cooperative Extension, and contributions by other payers and beneficiaries of the PCEP may be a reasonable start. To put this suggestion in another context, $\$ 500$ million is $13 \%$ less than the amount allocated by NIH to launch the National Center for Advancing Translational Science. ${ }^{36}$ Other federal and state agencies could contribute additional dollars for specific programs and projects.

Concrete steps should be taken at the federal, state, and local level. The federal government should appropriate the $\$ 120$ million annual funding for the PCEP authorized by the ACA, and target future appropriations to a $\$ 500$ million level, commensurate with that for the NIH National Center for Advancing 
Translational Science and the Cooperative Extension Program. Absent fulfilling the authorized funding level for the PCEP, the federal government should at a minimum appropriate funding to sustain the AHRQ IMPaCT grant program and its focus on assisting existing PCEP prototypes to disseminate their models. Many states have formed multi-stakeholder coalitions to advance reforms in primary care and community health, and these coalitions should develop clear strategic plans for a robust statewide infrastructure for facilitating primary care transformation. The Vermont Blueprint for Health approach can serve as a model for such statewide efforts, with state law requiring that all health plans contribute to a state-administered practice facilitation service that is "payer-ecumenical" and can assist with whole-practice transformation rather than being limited to only a subset of the population covered by a particular health plan.

States may also want to consider a transition model for their regional extension centers as federal funding ends, such that regional extension centers might extend their work beyond a narrow focus on electronic health records toward broader practice change. At the local level, coalitions exist in many communities that could incorporate the elements of a PCEP into their activities. For example, many county health departments and community hospitals collaborate on community health planning as part of the community health benefit activities hospitals are required to perform to maintain their non-profit tax exempt status. Primary care practices, community health centers, and other primary care stakeholders should be fully integrated into these types of local planning networks, with some of these community benefit resources directed to supporting a local PCEP. In addition, local and regional entities such as Independent Practice Associations and Physician Hospital Organizations that aggregate practices into networks and groups should function as much more than just contracting organizations and assume responsibility for helping practices to implement innovations in care delivery.

In conclusion, the rapid pace of change in health care demands that a PCEP be viewed as an essential, and not optional, ingredient for transformation of primary care and improvement of population health. Just as no hospital in the United States can rightfully operate without a quality and performance improvement department with dedicated staff and resources, it is unreasonable to expect an entire, foundational component of the health system - the primary care ambulatory sector-to function well without a comparable infrastructure to facilitate improvement and the continuous, adaptive changes that are the hallmarks of high performing organizations. Although the PCEP as delin- eated in the ACA represents one vision for a nationwide primary care improvement infrastructure, actions at the state and local level will be equally critical to building the systems needed to support practices and their communities in the journey of transformation.

To read or post commentaries in response to this article, see it online at http://www.annfammed.org/content/11/2/173.

Key words: primary care, change, organizational, health policy

Submitted September 3, 2012; submitted, revised, December 16, accepted January 8, 2013.

Acknowledgments: The authors wish to thank the Agency for Healthcare Research and Quality for funding a conference in 2010 that stimulated development of this article. We also thank Dr Wilson Pace for early advice on this manuscript, Dr Jo Ivey Boufford for her review of an early draft, and Kim Epperson for assistance with manuscript preparation.

\section{References}

1. Fleming C. Berwick brings the 'triple aim' to CMS. HealthAffairs Blog. 2010 Sep 14. http://healthaffairs.org/blog/2010/09/14/ berwick-brings-the-triple-aim-to-cms. Accessed Jun 2012.

2. Compilation Of Patient Protection and Affordable Care Act [As Amended Through May 1, 2010]. Primary Care Extension Program. Sec. 5405:582-585. Also Sec. 399v-1 O42 U.S.C. 280g-12. Primary Care Extension Program. http://housedocs.house.gov/energycommerce/ppacacon.pdf. Accessed Dec 2012.

3. Grumbach K, Mold JW. A health care cooperative extension service: transforming primary care and community health. JAMA. 2009;301 (24):2589-2591.

4. Grumbach K, Grundy P. Outcomes of Implementing Patient-centered Medical Home Interventions: A Review of the Evidence From Prospective Evaluation Studies in the United States. Washington, DC: PatientCentered Primary Care Collaborative; 2010. http://www.pcpcc.net/ files/evidence_outcomes_in_pcmh.pdf.

5. Fontaine $\mathrm{P}$, Flottemesch TJ, Solberg LI, Asche SE. Is consistent primary care within a patient-centered medical home related to utilization patterns and costs? J Ambul Care Manage. 2011;34(1):10-19.

6. Phillips RL Jr, Bronnikov S, Petterson S, et al. Case study of a primary care-based accountable care system approach to medical home transformation. J Ambul Care Manage. 2011;34(1):67-77.

7. Institute of Medicine. Primary Care and Public Health: Exploring Integration to Improve Population Health. Washington, DC: The National Academies Press; 2012.

8. Grumbach K, Bainbridge E, Bodenheimer T. Facilitating improvement in primary care: the promise of practice coaching. The Commonwealth Fund. June 11, 2012. http://www.commonwealthfund. org/Publications/Issue-Briefs/2012/Jun/Facilitating-Improvement-inPrimary-Care.aspx\#citation. Accessed Jun 2012.

9. Rasmussen W. Taking the University to the People: Seventy-five Years of Cooperative Extension. Ames, IA: lowa State University Press; 1989.

10. Birkhaeuser D, Evenson RE, Feder G. The economic impact of agricultural extension: A review, Economic Development and Cultural Change. Econ Dev Cult Change. 1991;39(3):607-650.

11. McGinnis L, Kaplan K, Comis D, Suszkiw J. A history of success with state and university partnerships. Agri Res. 2009;March. http:// www.highbeam.com/doc/1G1-195135071.html.

12. Berwick DM. Disseminating innovations in health care. JAMA. 2003; 289(15):1969-1975. 
13. Baskerville NB, Liddy C, Hogg W. Systematic review and metaanalysis of practice facilitation within primary care settings. Ann Fam Med. 2012;10(1):63-74.

14. Smith KD, Merchen E, Turner CD, Vaught C, Fritz T, Mold J. Improving the rate and quality of medicaid well child care exams in primary care practices. J Okla State Med Assoc. 2010;103(7):248-253.

15. Mold JW, Aspy CA, Nagykaldi Z; Oklahoma Physicians Resource/ Research Network. Implementation of evidence-based preventive services delivery processes in primary care: an Oklahoma Physicians Resource/Research Network (OKPRN) study. J Am Board Fam Med. 2008;21(4):334-344.

16. Aspy CB, Mold JW, Thompson DM, et al. Integrating screening and interventions for unhealthy behaviors into primary care practices. Am J Prev Med. 2008;35(5)(Suppl):S373-S380.

17. Aspy CB, Enright M, Halstead L, Mold JW; Oklahoma Physicians Resource/Research Network. Improving mammography screening using best practices and practice enhancement assistants: an Oklahoma Physicians Resource/Research Network (OKPRN) study. J Am Board Fam Med. 2008;21(4):326-333.

18. Agency for Healthcare Research and Quality. Practice Enhancement Assistants Improve Quality of Care in Primary Care Practices. Washington, DC: AHRQ Health Care Innovations Exchange, 2012. http:// innovations. ahrq.gov/content. aspx?id $=1768 \varepsilon \mathrm{tab}=1$.

19. Kaufman A, Powell W, Alfero C, et al. Health extension in new Mexico: an academic health center and the social determinants of disease. Ann Fam Med. 2010;8(1):73-81.

20. McCloskey J. Promotores as partners in a community-based diabetes intervention program targeting Hispanics. Fam Community Health. 2009;32(1):48-57.

21. Hogg W, Baskerville N, Lemelin J. Cost savings associated with improving appropriate and reducing inappropriate preventive care: cost-consequences analysis. BMC Health Serv Res. 2005;5(1):20.

22. Nagykaldi Z, Mold JW, Robinson A, Niebauer L, Ford A. Practice facilitators and practice-based research networks. J Am Board Fam Med. 2006;19(5):506-510.

23. Center for Medicare and Medicaid Innovations. The comprehensive primary care initiative. Center for Medicare \& Medicaid. http://innovations.cms.gov/initiatives/Comprehensive-Primary-Care-Initiative. html. Accessed Jun 2012.

24. Bitton A, Martin C, Landon BE. A nationwide survey of patient centered medical home demonstration projects. J Gen Intern Med. 2010;25(6):584-592.
25. National Academy for State Health Policy. Medical home $\&$ patientcentered care. NASHP. http://www.nashp.org/med-home-map. Accessed Jun 2012

26. Patient Centered Primary Care Collaborative. BCBSA Demonstration Project Release: Blue Cross and Blue Shield companies join primary care physician groups, national employers and consumer groups to explore new approach to patient care. http://www.pcpcc.net/content/bcbsa-demonstration-project-press-release. Accessed Jun 2012.

27. Center for Studying Health System Change. Liebhaber A, Grossman J. Physicians moving to mid-sized single-specialty practices. Tracking Report No. 18: Results from the Community Tracking Study. 2007 http://hschange.org/CONTENT/941/.

28. Highsmith N, Berenson J. Driving value in medicaid primary care: the role of shared support networks for physician practices. The Commonwealth Fund, March 2011. http://www.commonwealthfund. org/Publications/Fund-Reports/2011/Mar/Driving-Value-in-MedicaidPrimary-Care.aspx. Accessed Jun 2012.

29. Department of Vermont Health Access. Vermont Blueprint for Health: 2010 Annual Report. Williston, VT: Department of Vermont Health Access; 2011. http://hcr.vermont.gov/sites/hcr/files/final_annual_ report_01_26_11.pdf.

30. The Office of the National Coordinator for Health Information Technology. HITECH and Funding Opportunities. http://www. healthit.gov/policy-researchers-implementers/faqs/what-are-relatedcompanion-hitech-funding-opportunities. Accessed Feb 2013.

31. Zerhouni EA. Clinical research at a crossroads: the NIH roadmap. J Investig Med. 2006;54(4):171-173.

32. Knox L, Taylor EF, Geonnotti K, et al. Developing and Running a Primary Care Practice Facilitation Program: A How-to Guide. Rockville, MD: AHRQ Patient Centered Medical Home Resource Center; 2011.

33. Johnson D, Saavedra P, Sun E, et al. Community health workers and medicaid managed care in New Mexico. J Community Health. 2012;37(3):563-571.

34. HealthTeamWorks [website]. 2012. http://www.healthteamworks. org/. Accessed Jun 2012.

35. USDA National Institute of Food and Agriculture. Extension Activities Appropriation History: Fiscal Years 2000-2010. 2012. http:// www.csrees.usda.gov/about/offices/budget/10yr_exten_hist.pdf.

36. NIH establishes National Center for Advancing Translational Sciences: new center to speed movement of discoveries from lab to patients. NIH News. June 23, 2011. 